\title{
The Effectiveness of Applying Multimedia Web-Based Technologies in Culinary Skills Training
}

\author{
Liwei Hsu (Corresponding author) \\ National Kaohsiung University of Hospitality and Tourism \\ Taiwan \\ E-mail: liweihsu@mail.nkuht.edu.tw \\ Ming-Yu Chang Chien \\ Asia Senior Vocational High School \\ Taiwan
}

Received: July 29, 2015 Accepted: August 18, 2015 Published: September 16, 2015

doi:10.5296/ire.v3i2.8055 URL: http://dx.doi.org/10.5296/ire.v3i2.8055

\begin{abstract}
This study was designed to investigate the effectiveness of the use of multimedia web-based technologies in culinary skills training with a mixed method. One hundred high school students of hospitality programme in Taiwan were recruited and randomly assigned to experimental and control groups respectively using multimedia web-based educational technologies and traditional educational methods, with two dishes (one basic and one advanced) as target contents to be learned and delivered. The findings indicated that the experimental group performed better on both dishes. The effect size validated the applicability of multimedia web-based technologies in culinary skills training. A focus group of 10 interviewees from the experimental group were formed for qualitative part of research. Furthermore, results of focus group interviews revealed that convenience was mentioned by eight interviewees as a benefit of the experimental instructional method, while the ability to present material with captions was seen as the most significant functionality.
\end{abstract}

Keywords: Culinary skills training; multimedia; web-based learning; experimental research design 


\section{Introduction}

Information and communication technologies (ICTs) have changed the landscape of culinary arts and hospitality programme, and stakeholders have tried to keep up (Mandabach, Harrington, VanLeeuwen, \& Revelas, 2002). As more and more net-generation students (Oblinger \& Oblinger, 2005) enter these programs, it is suggested that pedagogical models should be adjusted to map to these students' attributes in learning (Tapscott, 2008). Technology-enabled learning (or other terms such as eLearning, online learning and/or digital learning which are widely used in the academia) has attracted considerable attention in academia (Ali, Murphy, \& Nadkarni, 2014; Liburd \& Christensen, 2013; Mitchell \& McConnell, 2012). With the advent of Web 2.0 technologies, students are able to engage in instruction activities as long as they have access to the Internet (Hsu, 2011). Under such circumstances, learning and teaching using technologies has become very popular (Mejia \& Phelan, 2014; Sciarini, Beck, \& Seaman, 2012).

In the same vein, more dynamic presentation of materials can be delivered through multimedia than via a text-based modality alone (Lowe, 2003). Multimedia refers to the integration of more than one mode of content presentation in a computer system (Fang \& $\mathrm{Lu}$, 2015; Surjono, 2015; Vaughan, 2011). But what is the precise nature of the benefits derived from multimedia? Tibus (2013) posited that presentation through multimedia per se did not affect learners' interpretation and elaboration of information, nor was any redundancy effect (i.e. if information are presented with pictures and narration simultaneously, on-screen text will be redundant and will lead to the increase of cognitive load, as cited in Toh, Munassar, \& Yahaya (2010)) was discovered when visual inputs were presented. However, some studies suggest that learners tend to have better comprehension as well as retention of content when it is presented as text (Furnham, 2002) because overwhelming information will cause cognition overloaded (Lowe, 2003). In other words, the effectiveness of teaching materials delivered through multimedia is still under debate, and little research has been conducted from the perspective of hospitality education (Ali et al., 2014).

Culinary education has been booming in the past decades; taking the United States as an example, there are more than 700 culinary training programs offered to prospective culinarians (Reinhart, 2000). Recently, quite a number of students have entered culinary training because of the positive professional image of chefs created by the media (Mandabach et al., 2002; Pratten, 2003; Steno \& Friche, 2015), and as a result of these media representations they have also come to have a clearer idea of what kinds of skills they should acquire before they finish the course (Müller, VanLeeuwen, Mandabach, \& Harrington, 2009). Researchers (Gursoy \& Swanger, 2004) further suggest that educational institutes should re-examine their curriculum design to face rapid changes in the food industry. Nevertheless, Severson (2007) points out that more and more graduates of culinary programs in the US identify a gap between the sometimes questionable quality of education and the pricy tuition fees and similar situation may also exist in other countries such as Taiwan. It is not easy to leverage the cost and quality of education, as Green (2014) notes, but new technologies may be a feasible solution (Singh \& Bajaj, 2015; Whalen \& Wright, 1999). Mandabach et al. (2002) similarly report that students in culinary training programs may desire that technology 
should be used more in curriculum design.

Even so, this issue has yet to be adequately explored (Schneckenberg, 2009). The present study is designed to provide empirical evidence to help do so, by addressing the following research questions:

1) Is there a significant difference in the effects of the treatment and control groups on culinary skills training as measured by the posttest?

2) What are culinary students' perceptions of the use of multimedia web-based technologies in their training?

In order to properly address the abovementioned research questions, pertinent literatures are reviewed and the research design including the selection of participants, the delivery of content, experimental and focus-group interview administration are introduced in details. Results of both quantitative and qualitative data are presented followed by the discussion, implication and conclusion stemmed from the results.

\section{Culinary Arts Training and Multimedia Web-based Technology}

There are a number of academic works give credits to the application of technology in hospitality education (Rakes \& Casey, 2002; Feinstein, Raab \& Stefanelli, 2005); however, most of these empirical works have caveats on the methodology of determining the effectiveness of such application (Feinstein \& Parks, 2002). For this reason, scholars such as Feinstein et al. (2005) propose the necessity of determining the effectiveness of various genres of instruction which includes the integration of technology in instruction. Such a statement echoes the postulation of Kluge (1996) “... It is time that hospitality educators get together and focus on significant amount of energy on defining the role of information technology in the hospitality curriculum" (p. 49).

Concerning the underpinning rationale of using multimedia in hospitality education, as Harris (1996) suggested, when multimedia technology is adopted in instruction, Skinner's theory of sensory-dependent learning which specify the importance of stimuli triggered by the technology to individual's learning outcome. Multimedia also has been considered as the prevalently tool used by teachers of hospitality program (Feinstein et al., 2005) because many previous studies indicated multimedia can provide learners with nonverbal information and thus is able to improve the comprehensibility of the contents being delivered (Salmon, 2014; Takacs, Swart, \& Bus, 2015; Verhallen, Bus, \& de Jong, 2006). However, it is to our knowledge that pertinent research about the possible advantages of adopting multimedia web-based technology in culinary skill training is scarce, particularly when Chinese culinary skills are at stake. Chinese cooking style seems to be much different from the western styles; for example, it applied frying ingredients in oil in a different way (Ko et al., 2000). Furthermore, Chinese chefs are always be proud of their cutting skills which they perceive would be much more sophisticated than western skills (Symons, 2002). It would be interesting to research these two under-explored field to extend our current understanding; therefore, the present study was designed and conducted to bridge this research gap. 


\section{Research Design}

In order to properly address the proposed research questions, the present study adopted a mixed method. Mixed method research design involves both quantitative and qualitative means of collecting, analyzing, and integrating (or mixing) data in a single study. The advantages of adopting the mix methods have been widely discussed and recognized in recently years (Onwuegbuzie, \& Leech, 2004) for their being able to "be more flexible and holistic in their investigative techniques" (p. 770). The quantitative data were retrieved from a quasi-experimental design whilst qualitative data were mainly from focus-group interviews. Details about the research design of this present study is presented as follows:

\subsection{Participants}

As advised by Bernard (2004), good control over participants selection is critical to the internal validity of any experimental design, and the best practice for most purposes will be to randomly assign the participants to controlled and experimental groups. Therefore, the present study adopted random selection. Furthermore, a well-design randomised experiment has been considered as the best method to examine the efficacy of any intervention (McGowan, 2011). Two groups of participants were chosen from 10 classes of students studying in hospitality programs at a private vocational high school in southern Taiwan. The study sample consisted of 100 students in all: 45 in the control group, 55 in the experimental group. This size has been considered large enough to acquire powerful statistical results (Girard, 2013).

Among the participants, 64 were female and the other 36, male. The average age was 16.2, with a standard deviation of 0.6. Detailed demographic data about the participants is presented in Table 1 below.

Table 1. Demographic Data of Participants

\begin{tabular}{|c|c|c|}
\hline Attributes of Participants $(\mathrm{N}=100)$ & $\mathrm{n}$ & $\%$ \\
\hline \multicolumn{3}{|l|}{ Age } \\
\hline 16 & 82 & 82 \\
\hline 17 & 16 & 16 \\
\hline 18 & 2 & 2 \\
\hline \multicolumn{3}{|l|}{ Gender } \\
\hline Male & 36 & 36 \\
\hline Female & 64 & 64 \\
\hline
\end{tabular}

Informed consent of the participants and their legal guardians was obtained to allow them to participate in the experimental study after they were briefed on its nature and purpose as well as the methods of teaching to be involved and the instruments that would be used (Johnson, 2008). The participants were also told that if desired, they would have the freedom to move to other groups participating in the course but not the experiment (that is, to leave the 
experiment) (Creswell, 2005).

\subsection{Delivery of Content}

The training course commenced after the participants were assigned to groups. For those in the experimental group, training was undertaken in a multimedia mode online, while their counterparts in the control group were trained in traditional face-to-face fashion. Both two groups were trained by the same instructor, and the target content were also identical. Participants in the control group convened six hours per week in the classroom, and those in the experimental group, for the same amount of time weekly via a Learning Management System (LMS) housed by the school. The multimedia delivery was prepared and produced by the research team. The demonstration, recording and postproduction (including adding the caption) were conducted by the research team. We used Sony HDR-XR350 Camcorder to record the demonstrations. When editing the video clips, the editing software Power Director version 8.0 was utilized. After the video clips were finished and transformed to Windows Media format, they were all stored in the LMS. Please refer to the appendices for the screenshots of the contents for details.

Participants were trained to acquire the culinary skills to prepare two popular Chinese dishes - Sakura Shrimp Fried Rice and Sweet \& Sour Pork Chop. The former is considered to be a dish needing basic skills to prepare, while the latter requires more advanced skills. For training in both dishes, the instructor first focused on the introduction of mise-en-place and the ingredients, followed by a demonstration of the preparation of the dish. All the participants were given the chance to practice their culinary skills in the kitchen on campus for five hours every week.

\subsection{Measurement}

Participants were asked to be examined on their knowledge of preparing the two dishes as well as their cooking skills. They were all evaluated through on-site observation by a panel of 3 judges who were experienced chefs from five-star hotels; additionally, they were also the judges recruited by the Ministry of Labor to issue the Certificate of Culinary Arts. This type of measurement was similar to the way students were to be tested in order to obtain Level-C Certificate of Culinary Art in Taiwan. Since the panellists were all professionals, the validity issue of the measurement should be alleviated.

\subsection{Quasi Experiment Procedure}

To establish comparability between the two groups, a series of possible confounding variables including the individual's prior knowledge and qualifications that might have affected the reliability of the experiment were examined with a pre-test to ensure that all participants, regardless of their cohort, had similar (though it is unrealistic to say 'the same') levels of skill and knowledge related to both dishes.

After the training programme was completed, all the participants were asked to take a post-test. Pre-tests and post-tests were about the knowledge and skills of preparing these two dishes and were assessed on a scale of 100 by two chefs of international chain hotels, and the 
consistency between their assigned grades was high (Cohen's Kappa = .81) (Landis \& Koch, 1997; Zinbarg, Yovel, Revelle, \& McDonald, 2006); one average score was used for each participant for the following statistical analyses. The quasi-experimental study presented here was an endeavour to provide empirical evidence on the first question, with a focus on discovering how web-based technologies can be effectively exploited in culinary skills training.

\subsection{Focus Group Interview}

According to Çakmak and Ustaolu (2015), a focus group is a small group of six to ten people led through an open discussion by a skilled moderator. This present study recruited 10 participants from the experimental group for the reason of being able to trigger discussion but without making any individual be left out (Krueger \& Casey, 2009). Therefore, after the post-tests, 3 participants from the cohort whose performance at post-test was one standard deviation above the mean, another 3 whose performance was one standard deviation below the mean, and 4 who fell in between were selected for a focus group interview. Such a selecting approach is considered an efficient way of collecting detailed information within a limited period of time (Wilson, 2012). These participants were asked about their perceptions of the experience of using multimedia web-based technologies in culinary skills training. The focus group interview was about 90 minutes. The focus group members were informed of the recording of the interviews and agreed that the content could be transcribed into text for qualitative analysis. The transcription was done by two student workers and their works were compared to ensure to accuracy of transcription.

\subsection{Data Analysis}

Quantitative data were analysed with descriptive statistics including means, standard deviations, and t-tests (statistical significance was defined using $\mathrm{p}<0.05$ ). However, it has been argued that finding differences in statistical significance between study groups is not a sufficient result for experimental studies, and that the extent of the difference reported as an effect size should also be taken into account (Dreder, 2005). Cohen's d was adopted to determine the effect size of the experimental treatment. Qualitative data acquired from focus group interviews were assessed interpretatively to discover similarities and differences between the selected participants' responses to the interview questions. All the quantitative and qualitative data were analyzed using the R programming language, version 3.1.3.

\section{Results}

To what extent do multimedia web-based technologies benefit culinary skills training?

The participants' pre-test and post-test performance preparing Sakura Shrimp Fried Rice and Sweet \& Sour Pork Chop is considered first. A two-sample t-test was adopted to study how these two groups performed on the respective tests. Table 2 depicts the details of these experimental results. 
Table 2. Pre-test and Post-Test Results

\begin{tabular}{lllllllll}
\hline & & \multicolumn{2}{c}{$\begin{array}{c}\text { Experimental } \\
\text { Group }\end{array}$} & \multicolumn{2}{c}{$\begin{array}{c}\text { Control } \\
\text { Group }\end{array}$} & t & p & Cohen's d \\
\cline { 3 - 6 } & & M & SD & M & SD & & & \\
\hline Pre-test & Sakura Shrimp Fried Rice & 68.98 & 13.06 & 65.13 & 15.79 & 1.31 & .19 & \\
& Sweet \& Sour Pork Chop & & & & & & & \\
& & & & & & & &
\end{tabular}

\begin{tabular}{lcccccccc} 
& & 65.25 & 14.31 & 62.53 & 18.54 & .81 & .42 & \\
\hline Post-test & Sakura Shrimp Fried Rice & 73.15 & 16.71 & 63.84 & 18.43 & 2.57 & $.01^{* *}$ & .53 \\
& Sweet \& Sour Pork Chop & & & & & & &
\end{tabular}

$\begin{array}{lllllll}70.36 & 17.71 & 57.82 & 18.45 & 3.44 & .00 * * * & .72\end{array}$

$* \mathrm{p}<.05, * * \mathrm{p}<.01, * * * \mathrm{p}<.001$

According to the data conveyed in Table 2, there was no significant difference between the two groups on the pre-test for either dishes $(t=1.31, p=.19>.05$ for Sakura Shrimp Fried Rice; $\mathrm{t}=.81, \mathrm{p}=.42>.05$ for Sweet \& Sour Pork Chop) which indicates that both groups had statistically identical culinary skills for both dishes at the beginning of the experiment.

The t-tests for the post-test, in contrast, showed that the two groups were significantly different on both dishes. Specifically, for Sakura Shrimp Fried Rice, $t=2.57, p=.01$, and the experimental group had a higher mean score $(\mathrm{M}=73.15$ to 63.84 for the control group) and lower standard deviation ( $\mathrm{SD}=16.71$ to 18.43 for the control group). For Sweet $\&$ Sour Pork Chop, the mean score of the experimental group was $70.36(\mathrm{SD}=17.71)$, and the control group had a mean score of $57.82(\mathrm{SD}=18.45), \mathrm{p}=.00$. This effect of the experiment treatment was examined with Cohen's d; the results indicated a medium-sized effect on both post-tests (.53 for Sakura Shrimp Fried Rice and .72 for Sweet \& Sour Pork Chop) (Cohen, 1998). Such results supported the assertion that multimedia web-based technologies have an effect on participants' culinary skills training.

What are culinary students' perceptions of the use of multimedia web-based technologies in their instruction?

Eight of the participants who were selected to participate in the focus group interview expressed a positive attitude toward the use of web-based technologies in culinary skills training. The remaining two did not directly comment on the effectiveness of this pedagogical approach, but nor did they show any negative perceptions. One of them (Student \# 10) commented:

I was not used to this kind of pedagogy. To be honest, I still cannot believe that culinary skills can be trained in this way. However, after this training programme, I have to admit that it is quite convenient to me to review the contents....

When asked about the most impressive feature of the approach, five participants proposed 
that getting access to learning without time and space limitations was the one that first came to mind. However, all of them emphasised that they were able to gain a better understanding of the instructor's cooking demonstration due to the use of a multimedia presentation with written (text) captions. A sample statement in this regard is that of Student \#1:

I like this new type of programme which enabled me to learn whenever and wherever I wanted to learn. It was also convenient for me to do the review. I could even review the details about mise-en-place and the ingredients when I was on the bus. More importantly, I was able to apprehend the instruction better with the presentation of captions, because the traditional way of teaching could not do this... I had to take notes in the past, which made me miss some important information

Another participant (Student \# 7) said the following:

This innovative way of training in culinary skills was so intriguing and convenient. I would never think it would work, but I think it worked quite well for me.... The attribute that I like the most about this web-based multimedia way of training was the captions. I did not have to keep notes all the time in the learning process, so I could concentrate on the instructor's demonstration.

Student \#6 agreed with this argument and further pointed out: 'If there were no captions available, I don't think I would benefit too much from this type of training....'

In summary, eight out of ten interview participants expressed that multimedia web-based technologies had and would benefit their culinary skills training and that convenience and the caption function were the two major features that this type of training benefited them the most.

\section{Discussion, Implications, and Conclusion}

This present research was designed to extend the current understanding of the effectiveness of the application of multimedia web-based technologies in culinary skills training. Given the nature of this study, which required the identification of the participants' level of culinary skills before and after the experiment, both pre-test and post-test included two tests, one basic (Sakura Shrimp Fried Rice) and one was advanced (Sweet \& Sour Pork Chop). Pre-test results showed that all the participants had similar prior knowledge and skills of the two levels of dishes; therefore, the post-tests were able to demonstrate the effectiveness of these two modes of learning and teaching. The first research question was addressed by a two-sample t-test that indicated significant differences between groups; subsequently, Cohen's d was applied, and showed a medium effect size of multimedia web-based technologies used to learn basic and advanced culinary skills $(\mathrm{d}=.53$ and .72 respectively).

Such results echo the statement of Jaleel and Verghis (2015), who proposed that multimedia delivery of content can facilitate the dissemination of knowledge efficiently and effectively, particularly when web-based technologies are exploited. However, Mayer (2010) and Surjono (2015) advise that excessive use of multimedia may or may not lead to effective learning, and Takacs, Swart, and Bus (2015) postulated that visual information would distract learners' 
attention. The experimental study of Rummer, Schweppe, Fürstenberg, Scheiter, and Zindler (2011) further specified that complexity of multimedia information would increase mental effort and thus hinder the learning outcomes, but this finding was not in line with the present study's results. In fact, this study's results were directly opposite those of Rummer et al. (2011), because the effect size of multimedia web-based technologies was higher for the more complex culinary skills. One possible reason for this difference may be the nature of the target content. Different subject matter requires different levels of mental effort and mindfulness and thus different levels of concentration in the learning process. Future research may therefore usefully conduct inter-disciplinary comparison on the effectiveness of the use of multimedia presentation in web-based learning. Another reason for these differences may be that learners tend to pay more attention and allot more time to content if they are aware that it is going to be relatively complex. This statement needs more exploration and future research may shed light on it. In summary, the results of this study provided empirical evidence to support the use of multimedia web-based technologies in culinary skills training.

Concerning the participants' perceptions of the use of multimedia web-based learning in culinary skills training, the convenience of this approach was the benefit mentioned by the most participants, but the caption functionality was the most impressive aspect to them. Using the captions, the participants were able to pay more attention to the instructor's demonstration instead of focusing on catching or guessing what the instructor was saying. This result reflects Mayer's (2003) cognitive load theory of multimedia learning, which states that deeper learning can be triggered by the presentation of both verbal and nonverbal information. Therefore, Jaleel and Verghis, (2015) argued, '[m]ultimedia technologies can make a great contribution to the educators' ability to transfer and share valuable knowledge to learners' (p. 11), including in culinary skills training. Singh (2003) proposed that multimedia will have optimal effectiveness for teaching and learning if learners have low prior knowledge on the subject matter, if they have weak learning motivation, and if the multimedia approach is appropriately designed. The present study can suggest a fourth condition in addition to these three: complicated content presented through multimedia should provide with more visual cues such as captions for better comprehension.

One final important point needs to be raised by the present study: Computer competency is considered by culinary educators to be a basic requirement for culinary graduates (Mandabach et al., 2002), and learning using state-of-the-art technologies may benefit students' computer competency. However, a major downside of applying web-based technologies may be a lack of opportunities for face-to-face communication and kitchen communications of evident importance for real-world practice (Müller et al., 2009). Culinary educators who aim to apply web-based technologies in instruction may need to think further about this issue.

\section{Acknowledgement}

The author would like to dedicate his greatest gratitude to the Ministry of Science and Technology, Taiwan for the financial support (102-2511-S-328-002-). 


\section{References}

Ali, A., Murphy, H. C., \& Nadkarni, S. (2014). Hospitality students' perceptions of digital tools for learning and sustainable development. Journal of Hospitality, Leisure, Sport \& Tourism Education, 15, 1-10. http://dx.doi.org/10.1016/j.jhlste.2014.02.001

Bernard, R., Abrami, P., Lou, Y., \& Borokhovski, E. (2004). A methodological morass? How we can improve quantitative research in distance education. Distance Education, 25(2), 175-198. http://dx.doi.org/10.1080/0158791042000262094

Cohen, J. (1998). Statistical power analysis for the behavioral science $\left(2^{\text {nd }}\right.$ ed.). New Jersey: Lawrence Erlbaum Associates

Creswell, J. (2005). Educational research: Planning, conducting, and evaluating quantitative and qualitative research (2nd ed.). Upper Saddle River: Pearson.

Çakmak, C., \& Ustaolu, M. (2015). Post-Conflict Syrian State and Nation Building: Economic and Political Development. Palgrave Macmillan.

Dreder, A. (2005). Statistical testing of hypotheses in psychological, educational and social research. Cairo, Egypt: The World of Books.

Fang, M., \& Lu, X. (2015, January). On Multimedia Teaching and Multimedia Software. In International Conference on Education, Management, Commerce and Society (EMCS-15). Atlantis Press. http://dx.doi.org/10.2991/emcs-15.2015.60

Feinstein, A. H., \& Parks, S. (2002). The Use of Simulation in Hospitality as Analytic Tool and Instructional System: A Review of the Literature. Journal of Hospitality and Tourism Research, 26(4), 396-421. http://dx.doi.org/10.1177/109634802237486

Feinstein, A. H., Raab, C., \& Stefanelli, J. M. (2005). Educational technology research in the hospitality industry. Journal of Hospitality \& Tourism Education, 17(4), 9-18. http://dx.doi.org/10.1080/10963758.2005.10696837

Furnham, A., De Siena, S., \& Gunter, B. (2002). Children's and adults' recall of children's news stories in both print and audio-visual presentation modalities. Applied Cognitive Psychology, 16(2), 191-210. http://dx.doi.org/10.1002/acp.777

Girard, C., Ecalle, J., \& Magnan, A. (2013). Serious games as new educational tools: how effective are they? A meta-analysis of recent studies. Journal of Computer Assisted Learning, 29(3), 207-219. http://dx.doi.org/10.1111/j.1365-2729.2012.00489.x

Green, D. (2014). What is quality in higher education? Retrieved from http://repositorio.ub.edu.ar:8080/xmlui/bitstream/handle/123456789/2124/6.pdf? sequence=1

Gursoy, D., \& Swanger, N. (2004). An industry-driven model of hospitality curriculum for programs housed in accredited colleges of business. Journal of Hospitality \& Tourism Education, 16(4), 13-20. http://dx.doi.org/10.1080/10963758.2004.10696804

Harris, K. J. (1996). International Hospitality Marketing on the Internet: Project "Interweave." International Journal of Hospitality Management, 15(2), 155-163. 
http://dx.doi.org/10.1016/0278-4319(96)00017-5

Hsu, L. (2011). The perceptual learning styles of hospitality students in a virtual learning environment: The case of Taiwan. Journal of Hospitality Leisure Sport \& Tourism Education, 10(1), 114-127. http://dx.doi.org/10.3794/johlste.101.325

Jaleel, S., \& Verghis, A. M. (2015). Knowledge Creation in Constructivist Learning. Universal Journal of Educational Research, 3(1), 8-12.

Johnson, B., \& Christensen, L. (2008). Educational research: Quantitative, qualitative, and mixed approaches. Sage.

Kluge, E. A. (1996). A Literature Review of Information Technology in the Hospitality Curriculum. Hospitality ResearchJournal, 19(4), 45-64.

Krueger, R. A., \& Casey, M. A. (2009). Focus groups: A practical guide for applied research. Sage.

Ko, Y. C., Cheng, L. S. C., Lee, C. H., Huang, J. J., Huang, M. S., Kao, E. L., ... Lin, H. J. (2000). Chinese food cooking and lung cancer in women nonsmokers. American journal of epidemiology, 151(2), 140-147.

Landis, J. R., \& Koch, G. G. (1977). The measurement of observer agreement for categorical data. Biometrics, 159-174.

Liburd, J. L., \& Christensen, I. F. (2013). Using web 2.0 in higher tourism education. Journal of Hospitality Leisure, Sport \& Tourism Education, 12(1), 99-108.

Lowe, R. K. (2003). Animation and learning: selective processing of information in dynamic graphics. Learning and instruction, 13(2), 157-176.

Mandabach, K. H., Harrington, R., VanLeeuwen, D., \& Revelas, D. (2002). Culinary education and computer technology: A longitudinal study. Journal of Hospitality \& Tourism Education, 14(2), 9-15.

Mayer, R. E. (2003). The promise of multimedia learning: using the same instructional design methods across different media. Learning and Instruction, 13, 125-139. http://dx.doi.org/10.1016/s0959-4752(02)00016-6

Mayer, R. E. (2010). Applying the science of learning to medical education. Medical Education, 44, 543-549.

McGowan, H. M. (2011). Planning a comparative experiment in educational settings. Journal of Statistics Education, 19(2), 1-18.

Mejia, C., \& Phelan, K. V. (2014). Hospitality Instructors' Preference for Blended Teaching: A Bridge to Full Online Course Delivery? Journal of Teaching in Travel \& Tourism, 14(4), 343-364.

Mitchell, A. W., \& McConnell, J. R. (2012). A historical review of contemporary educational psychology from 1995 to 2010. Contemporary Educational Psychology, 37(2), 136-147. 
http://dx.doi.org/10.1016/j.cedpsych.2011.11.001

Müller, K. F., VanLeeuwen, D., Mandabach, K., \& Harrington, R. J. (2009). The effectiveness of culinary curricula: A case study. International Journal of Contemporary Hospitality Management, 21(2), 167-178.

Oblinger, D., \& Oblinger, J. (2005). Is it age or IT: First steps toward understanding the net generation. Educating the Net Generation, 2(1-2), 20.

Onwuegbuzie, A. J., \& Leech, N. L. (2004). Enhancing the interpretation of significant findings: The role of mixed methods research. The Qualitative Report, 9(4), 770-792.

Pratten, J. D. (2003). What makes a great chef? British Food Journal, 105(7), 454-459.

Rakes, G. C., \& Casey, H. B. (2002). An Analysis of Teacher Concerns toward Instructional Technology. International Journal of Educational Technology, 3(1). Retrieved August 25, 2005, from http://www.ao.uiuc.edu/ijet/v3n1/rakes/index.html

Reinhart, P. (2000). Are Culinary Schools The New Apprenticeship? IACP Food Forum, 4th Quarter 2000, 23-24.

Rummer, R., Schweppe, J., Fürstenberg, A., Scheiter, K., \& Zindler, A. (2011). The perceptual basis of the modality effect in multimedia learning. Journal of Experimental Psychology: Applied, 17(2), 159-173.

Salmon, L. (2014). Factors that affect emergent literacy development when engaging with electronic books. Early Childhood Education Journal, 42, 85-92. doi:10.1007/s 10643-013-0589-2

Schneckenberg, D. (2009). Understanding the real barriers to technology-enhanced innovation in higher education. Educational Research, 51(4), 411-424.

Sciarini, M., Beck, J., \& Seaman, J. (2012). Online learning in hospitality and tourism higher education worldwide: A descriptive report as of January 2012. Journal of Hospitality \& Tourism Education, 24(2/3), 41-44.

Severson, K. (2007). "Top chef dreams crushed by student loan debt”, The New York Times, 8 May, pp. 1, 20.

Singh, V. K. (2003). Does Multimedia really improve learning effectiveness. In Asia Pacific Conference on Education, Re-envisioning Education: Innovation and Diversity, Singapore.

Singh, K., \& Bajaj, J. S. (2015). Using technology to deliver cost-effective Continuing Professional Development (CPD). Annals of National Academy of Medical Sciences (India), 51(1 \& 2), 45-53.

Steno, A. M., \& Friche, N. (2015). Celebrity chefs and masculinities among male cookery trainees in vocational education. Journal of Vocational Education \& Training, 67(1), 47-61.

Surjono, H. D. (2015). The effects of multimedia and learning style on student achievement in online electronics course. Turkish Online Journal of Educational Technology, 14(1). 
Symons, M. (2002). Cutting up cultures. Journal of Historical Sociology, 15(4), 431-450.

Takacs, Z. K., Swart, E. K., \& Bus, A. G. (2015). Benefits and Pitfalls of Multimedia and Interactive Features in Technology-Enhanced Storybooks A Meta-Analysis. Review of Educational Research, 0034654314566989.

Tapscott, D. (2008). Grown up digital: How the Net generation is changing your world. New York: McGraw-Hill.

Tibus, M., Heier, A., \& Schwan, S. (2013). Do films make you learn? Inference processes in expository film comprehension. Journal of Educational Psychology, 105(2), 329.

Toh, S. C., Munassar, W. A. S., \& Yahaya, W. A. J. W. (2010). Redundancy effect in multimedia learning: A closer look. Curriculum, Technology \& Transformation For An Unknown Future. Proceedings Ascilite Sydney, 988-998.

Vaughan, T. (2011). Multimedia: Making it works. (8th Ed.). New York: McGraw Hill

Verhallen, M. J. A., Bus, A. G., \& de Jong, M. T. (2006). The promise of multimedia stories for kindergarten children at risk. Journal of Educational Psychology, 98, 410-419. http://dx.doi.org/10.1037/0022-0663.98.2.410

Whalen, T., \& Wright, D. (1999). Methodology for cost-benefit analysis of web-based telelearning: Case study of the bell online institute. American Journal of Distance Education, 13(1), 24-44.

Wilson, V. (2012). Research methods: Focus groups. Evidence Based Library and Information Practice, 7(1), 129-131.

\section{Appendix}

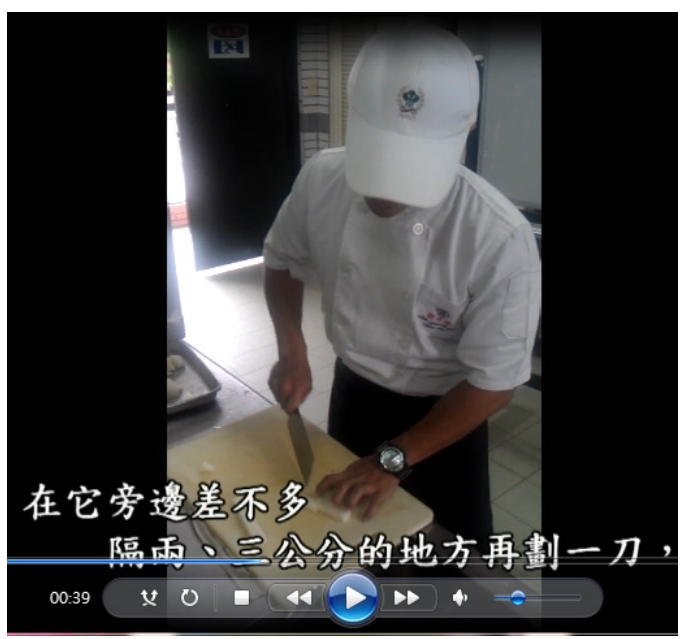

Figure 1. The instructor demonstrated the Chinese culinary style cutting skills with Chinese subtitle

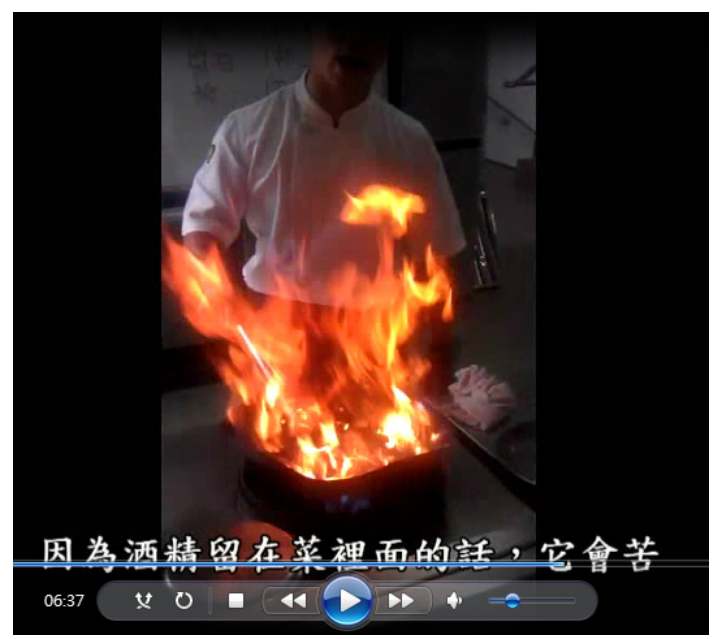

Figure 2. Demonstration of Chinese style sauté and the attention needed to be paid hen doing it 


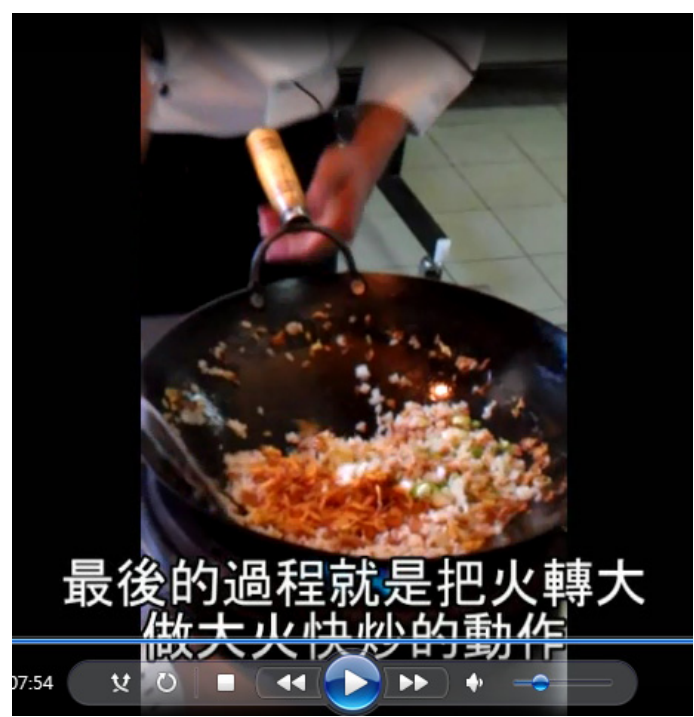

Figure 3. Demonstrating the cooking skills of Fired Rice

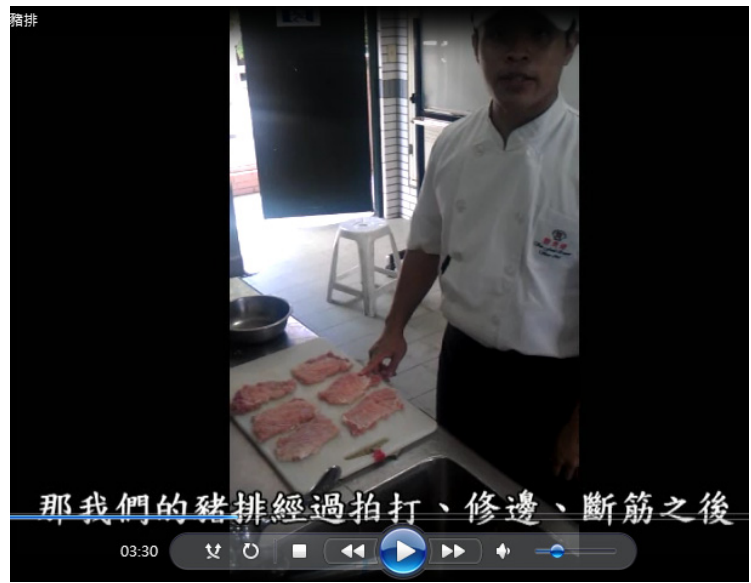

Figure 4. Explaining how to prepare the pork chop

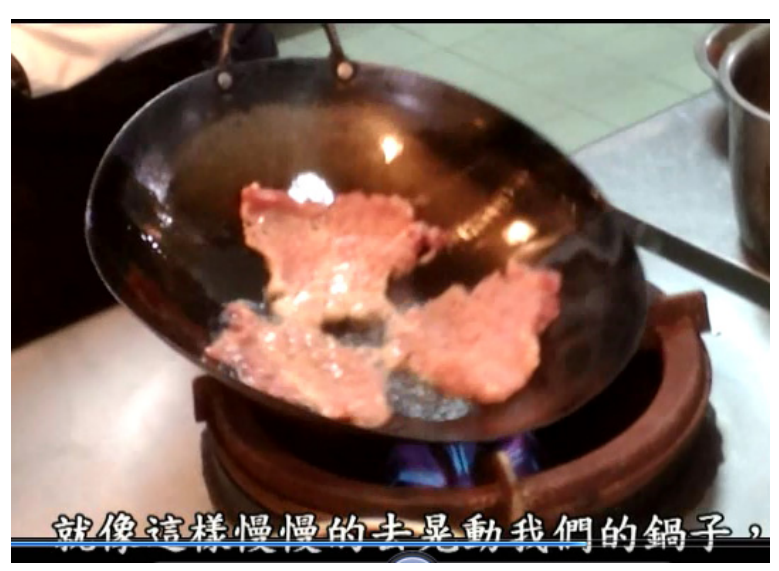

Figure 5. Demonstrating the culinary skills of stir-fry of the pork chops

\section{Copyright Disclaimer}

Copyright reserved by the authors.

This article is an open-access article distributed under the terms and conditions of the Creative Commons Attribution license (http://creativecommons.org/licenses/by/3.0/). 